\title{
The microphysics of clouds over the Antarctic Peninsula - Part 1: Observations
}

\author{
Tom Lachlan-Cope ${ }^{1}$, Constantino Listowski ${ }^{1}$, and Sebastian O'Shea ${ }^{2}$ \\ ${ }^{1}$ British Antarctic Survey, NERC, High Cross, Madingley Rd, Cambridge, CB3 OET, UK \\ ${ }^{2}$ School of Earth, Atmospheric and Environmental Sciences, University of Manchester, Oxford Road, \\ Manchester, M13 9PL, UK \\ Correspondence to: Tom Lachlan-Cope (tlc@bas.ac.uk)
}

Received: 15 April 2016 - Published in Atmos. Chem. Phys. Discuss.: 27 May 2016

Revised: 20 October 2016 - Accepted: 25 October 2016 - Published: 19 December 2016

\begin{abstract}
Observations of clouds over the Antarctic Peninsula during summer 2010 and 2011 are presented here. The peninsula is up to $2500 \mathrm{~m}$ high and acts as a barrier to weather systems approaching from the Pacific sector of the Southern Ocean. Observations of the number of ice and liquid particles as well as the ice water content and liquid water content in the clouds from both sides of the peninsula and from both years were compared. In 2011 there were significantly more water drops and ice crystals, particularly in the east, where there were approximately twice the number of drops and ice crystals in 2011.

Ice crystals observations as compared to ice nuclei parameterizations suggest that secondary ice multiplication at temperatures around $-5{ }^{\circ} \mathrm{C}$ is important for ice crystal formation on both sides of the peninsula below $2000 \mathrm{~m}$. Also, back trajectories have shown that in 2011 the air masses over the peninsula were more likely to have passed close to the surface over the sea ice in the Weddell Sea. This suggests that the sea-ice-covered Weddell Sea can act as a source of both cloud condensation nuclei and ice-nucleating particles.
\end{abstract}

\section{Introduction}

There have been very few in situ measurements of cloud microphysical properties over the Antarctic continent (Bromwich et al., 2012; Lachlan-Cope, 2010). However, there is evidence, from surface radiation measurements, that clouds are poorly represented within numerical models over Antarctica (King et al., 2015; Bromwich et al., 2013) and over the surrounding oceans (Flato et al., 2013; Bodas-
Salcedo et al., 2014). To correct these errors in climate (and forecast) models, a better understanding of the microphysical processes controlling these clouds is needed. In situ observations of cloud and aerosol properties over the Antarctic continent are required to develop and validate model parameterizations of these clouds. This paper presents observations that start to address this issue.

The main part of the Antarctic continent is an ice sheet that rises to over $4000 \mathrm{~m}$ above sea level (m a.s.l.). Coming off this continental mass and heading north towards South America is the Antarctic Peninsula (see Fig. 1). The Antarctic Peninsula is less than $100 \mathrm{~km}$ wide for the most part and rises to over $3000 \mathrm{~m}$ in places. Although isolated measurements have been made over the main continent (Belosi et al., 2014), more measurements have been made over the peninsula. Measurements of ice-nucleating particles (INPs) have been made at Palmer Station $\left(64^{\circ} 46^{\prime} 27^{\prime \prime} \mathrm{S}, 64^{\circ} 03^{\prime} 11^{\prime \prime} \mathrm{W}\right)$ (Saxena, 1983), and direct measurements have been made from the surface of cloud particle phase and size from a field camp on the spine of the peninsula (Lachlan-Cope et al., 2001). During the austral summer in 2010 and 2011 measurements of basic meteorological parameters, turbulence and cloud microphysical properties were taken using the British Antarctic Survey's (BAS) instrumented Twin Otter aircraft, and it is these measurements that are considered here. Some of these data from four flights in 2010 have already been published (Grosvenor et al., 2012), but that work concentrated on the ice crystals present, while here we consider both the liquid and ice present in the clouds on 24 flights during the two campaigns. Results are presented on the number of liq- 

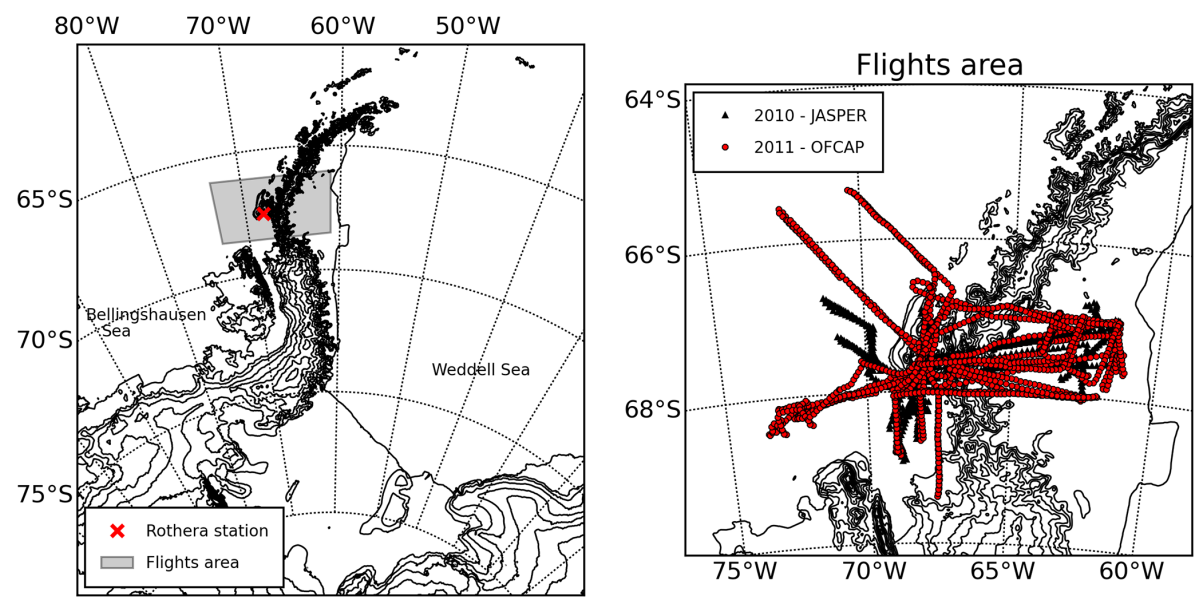

Figure 1. (Left panel) The Antarctic Peninsula and flight area in context, with the BAS Rothera station indicated (red cross). On the peninsula's eastern side is the ice-covered Weddell Sea. Solid lines indicate topographical features as well as ice shelves' boundaries. (Right panel) Close-up on the flight area showing the flight tracks of both campaigns of interest with black triangles (February 2010) and red circles (January 2011). Topography derived by Fretwell et al. (2013).

uid drops and ice particles present in the clouds as well as the liquid water content (LWC) and ice water content (IWC).

As observations were made on both sides of the Antarctic Peninsula, there is an opportunity to see if the cloud microphysical properties vary from one side to the other. The western side of the peninsula is exposed to the Southern Ocean, which, in the summer at least, is relatively ice-free. However, on its eastern side, the peninsula is bordered by the western part of the Weddell Sea, which remains largely ice-covered for most of the year. If the main source of cloud condensation nuclei $(\mathrm{CCN})$ were from the ocean surface, it would be expected that the total number of liquid droplets would be different from one side to the other. This hypothesis is supported by results from the Goddard Chemistry Aerosol Radiation and Transport model (GOCART) simulations (see Fig. 1 of Thompson and Eidhammer (2014)), which show sharp discontinuity in sea salt aerosols across the Antarctic Peninsula in February, with concentrations on the western side at least twice as large as on the eastern side. However the GOCART simulations do not include sources of aerosol within the sea ice pack that have been suggested by some authors (Yang et al., 2008). This paper is organized as follows: in Sect. 2 the observations obtained from the two aircraft campaigns are presented. The results from both years and both sides of the Antarctic Peninsula for liquid droplets, ice crystals, and aerosols are analysed in Sect. 3. In Sect. 4 the results are discussed and suggestions are made for the most plausible explanations of the temporal and regional differences observed in clouds and aerosols across the peninsula. Section 5 summarizes the findings and concludes on the possible implications of the results. Part 2 of this paper will look at the application of these observations to numerical modelling.

\section{Observations}

\subsection{Aircraft measurements}

Two airborne field campaigns were performed during February and March 2010, and January and February 2011, based at Rothera Research Station $\left(67^{\circ} 34^{\prime} \mathrm{S}, 68^{\circ} 08^{\prime} \mathrm{W}\right)$ on the Antarctic Peninsula. During these two periods, flights were made to study a variety of meteorological phenomena, including boundary layer (Fiedler et al., 2010), orographic flow (Elvidge et al., 2014), and cloud studies. A total of 64 flights were completed during these periods. This paper mainly considers 24 of these flights (12 per year) where detailed cloud microphysical measurements were collected. Fig. 1 shows the flight tracks of these 24 cloud flights over the two periods. The sampling took place on both sides of the peninsula, flying between 61 and $73^{\circ} \mathrm{W}$. The predominant cloud types by far were stratus or altostratus, normally in multiple thin layers. A cross-section, across the peninsula, of the flight tracks is shown in Fig. 2. It should be noticed that the flights in 2010 did not go as far west and that sampling on the western side of the peninsula was largely limited to altitudes below $2000 \mathrm{~m}$ west of $69^{\circ} \mathrm{W}$.

The observations were made with the British Antarctic Survey's instrumented Twin Otter aircraft (see King et al., 2008). This aircraft is fitted with a variety of instruments to measure temperature, humidity, radiation, turbulence, and surface temperature. The aircraft was also fitted with a Droplet Measurement Technology Cloud, Aerosol, and Precipitation Spectrometer (CAPS) (Baumgardner et al., 2001) carried on a wing-mounted pylon.

The CAPS instrument contains three discrete instruments: the Cloud and Aerosol Spectrometer (CAS), the Cloud Imaging Probe (CIP), and the Hotwire LWC Sensor. Data from the 


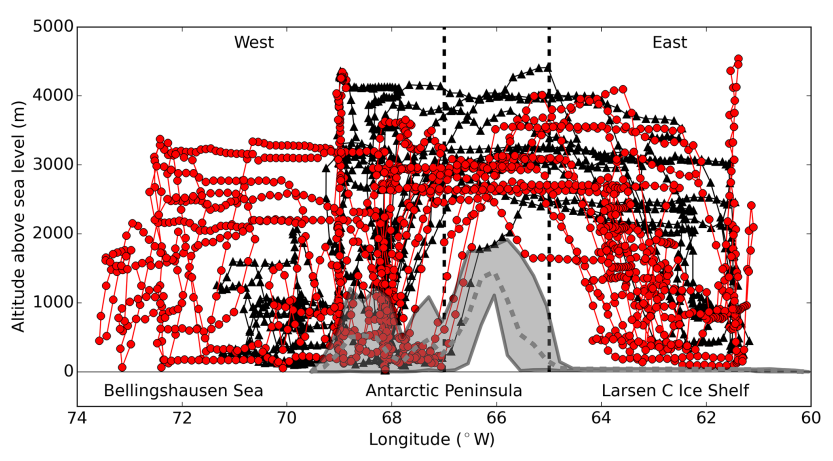

Figure 2. Latitudinal cross-section of flight tracks showing altitudes probed on both sides of the peninsula. February 2010 (black triangles) and January 2011 (red circles). The grey shaded area delimits the maximum and minimum topography height (at $5 \mathrm{~km}$ resolution) between 68 and $67^{\circ} \mathrm{S}$, and the grey dashed line shows the average topography height across the latitudes 68 to $67^{\circ} \mathrm{S}$. The vertical dashed lines delimit the western $\left(74-67^{\circ} \mathrm{W}\right)$ and eastern $(65-$ $60^{\circ} \mathrm{W}$ ) regions of the peninsula as defined in this study.

LWC sensor were only used in this study to help validate the CAS data. The CAS and CIP are described in turn below.

The CAS measures the diameter of particles between 0.5 and $50 \mu \mathrm{m}$ at a frequency of $1 \mathrm{~Hz}$. While the CAS used in this campaign did not have a full anti-shatter inlet, some modifications had been made to reduce the effect of shattering on the inlet by removing the shroud that was originally fitted to the inlet. A previous study (Grosvenor et al., 2012) has already looked at a small subset of these data and reported errors with the data from the CAS instrument. In particular, it appeared to be over-counting when integrated water content from the CAS was compared with the LWC sensor. After investigation this was found to be due to the air accelerating in the tube of the CAS instrument. Studies in the Cambridge University Markham wind tunnel using a fine pitot tube to measure the speed-up within the tube showed an increase that would result in the count being increased by 1.47 , and this has been accounted for in this latest study. When this correction is applied, the liquid water content calculated by integrating the CAS data for most flights agrees within $15 \%$ with the Hotwire LWC Sensor - part of this discrepancy is attributed to the Hotwire LWC Sensor's tendency to underread at high values of LWC.

The CIP images particles between a diameter of $25 \mu \mathrm{m}$ and $1.5 \mathrm{~mm}$, with $25 \mu \mathrm{m}$ pixel resolution, and had not at the time of this campaign been fitted with anti-shatter tips. However, a study of the particle inter-arrival times indicated very few shattered particle, and these were removed by eliminating particles that arrive within $1 \mu \mathrm{s}$. This study only uses data from the CAS and CIP, although the hotwire was used to help validate the CAS data.

The CIP instrument produces shadow images of the larger cloud particles and small precipitation size particles onto a charge-coupled device (CCD) array. Data processing is per- formed on these images to derive size-segregated ice crystal and large liquid drop number concentrations. Particles that are imaged by the extreme ends of the CCD array are rejected, and this means that the effective collection volume, used to calculate the concentration, gets smaller as the particles get larger. Further details concerning the data processing and quality control of the CIP images can be found in Crosier et al. (2011). Particles are separated into ice and liquid categories based on their circularity, $C$ :

$C=P^{2} / 4 \pi A$,

where $P$ is the measured particle perimeter and $A$ is the measured particle area (a minimum area of 50 pixels - equivalent to a spherical particle with a diameter of $200 \mu \mathrm{m}$ - is used as smaller particles are not sufficiently resolved to discriminate between drops and crystals). Following previous studies (Crosier et al., 2011; Taylor et al., 2016), particles with circularities between 0.9 and 1.2 are classified as circular and therefore liquid drops. For particles with values from 1.2 to 1.4 the decision on whether to count the particles as liquid or ice was made on a flight-by-flight case after looking at images. Particles with values over 1.4 were always counted as ice. The efficacy of the phase separation and choice of the circularity thresholds was confirmed by examining the sorted images "by eye". The ice water content was calculated using the Brown and Francis mass-dimension parameterization (Brown and Francis, 1995).

For this study it has been assumed that the clouds are mostly mixed-phase clouds and that the particles observed by the CAS (less than $50 \mu \mathrm{m}$ ) are all liquid, while the CIP particles are characterized as either liquid drops or ice depending on the value of their circularity (see above). The number of large liquid drops (greater than 50 pixels $-200 \mu$ m equivalent diameter) seen by the CIP is very small on all flights. The total number of particles seen by the CIP is much lower than that observed by the CAS, and the number of particles seen by the CIP (less than 50 pixels - equivalent to a circular drop of $200 \mu \mathrm{m}$ diameter) is for all flights less than $2-3 \%$ of the number seen by the CAS; thus we have ignored these particles whose phase we do not know. The version of the CAS probe used for this study was not able to measure polarization, and so it was not possible to attempt to discriminate between solid and liquid with the CAS. However, it seems likely that the assumption that all CAS particles are liquid is valid since we find that the liquid water calculated assuming the CAS particles are all liquid agrees reasonably with that calculated from the hotwire probe on the CAPS (as stated above). Moreover we see a distinct peak (not shown) in the CAS size spectra when in mixed-phase clouds, indicative of drop formation.

In this study the average cloud properties over all the flights shown in Fig. 1 are considered. Each flight did not go to every longitude bin, and even when a flight visited a longitude bin it did not necessarily enter a cloud. For example for the bin nearest Rothera the temperature and humidity 

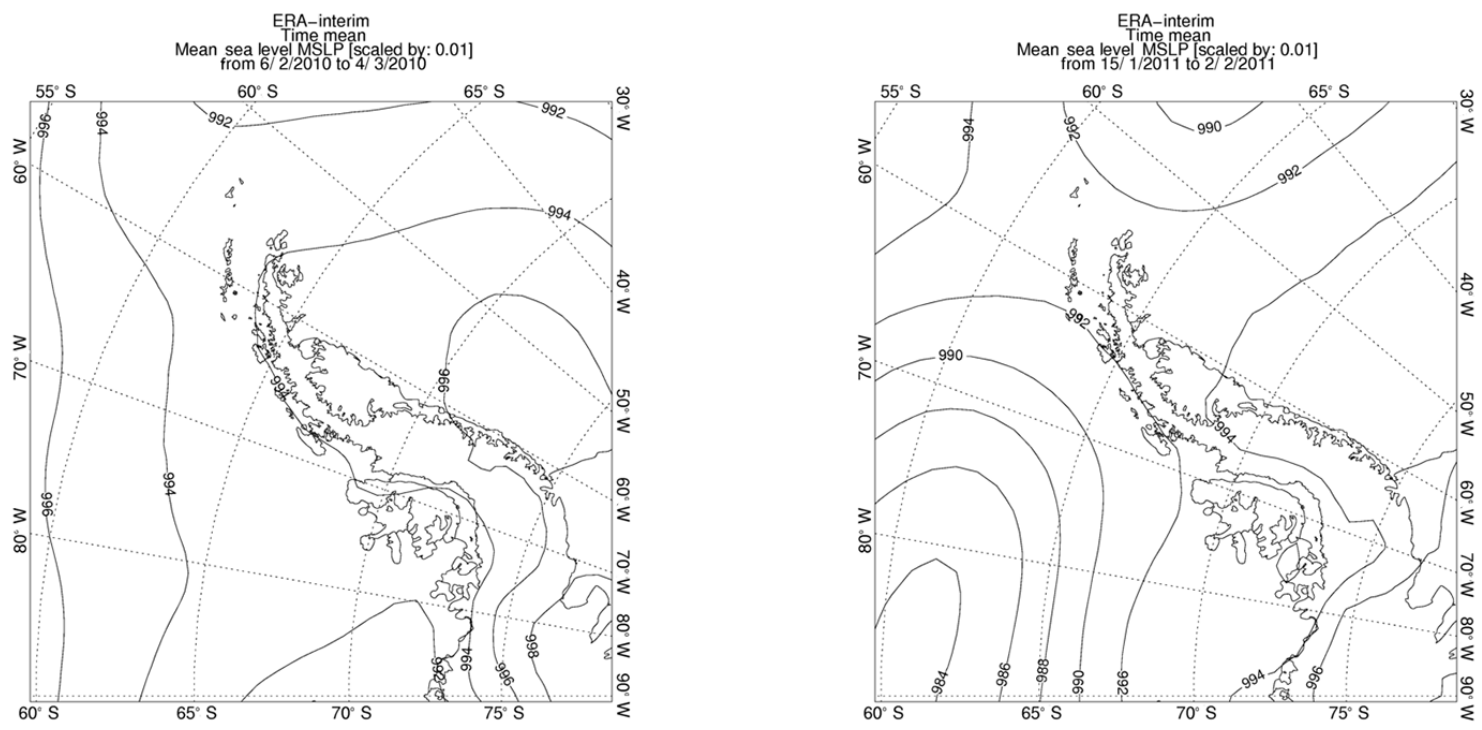

Figure 3. Mean sea level pressure from the ERA-Interim reanalysis for the periods of the aircraft campaign in 2010 (left) and 2011 (right).

show a large number of points as most flights will have data in this bin. For the cloud parameter graphs there are fewer points as it was normal to avoid clouds during take-off and landing and flying close to the mountains.

The CAS instrument has also been used to examine the aerosol concentrations outside clouds. To improve statistics, all flights made in the study area during 2010 and 2011 when the CAPS probe was operational have been used. This includes an extra 31 flights that were conducted primarily to investigate the boundary layer or the large-scale flow but still had clouds present in the sky. To ensure that these measurements only include cloud-free conditions, the data were filtered by removing periods when there were particles larger than $1 \mu \mathrm{m}$. The CAS instrument only measures particle larger than $0.5 \mu \mathrm{m}$ and so only gives us a measure of the larger aerosols, but it is assumed that this will bear some relation to the number of CCN and INPs available. In the case of INPs the relationship between aerosols greater than $0.5 \mu \mathrm{m}$ and INPs is represented in the parameterizations developed by DeMott et al. (2010).

\subsection{Meteorological conditions}

Figure 3 shows the mean sea level pressure from the ERAInterim reanalysis for the periods of the two campaigns. The flow during 2010 is generally slack, while in 2011 the Amundsen Sea low to the west of the Antarctic Peninsula has intensified and moved east. This brought a more northerly flow across western side of the peninsula, and this could be expected to bring warmer air. However, looking at the temperatures as a function of longitude from the aircraft flights in Fig. 4, we see that 2011 is actually colder in the west, and this is also seen in the temperature fields from the ERAInterim reanalysis as well as in the radiosonde ascents per-

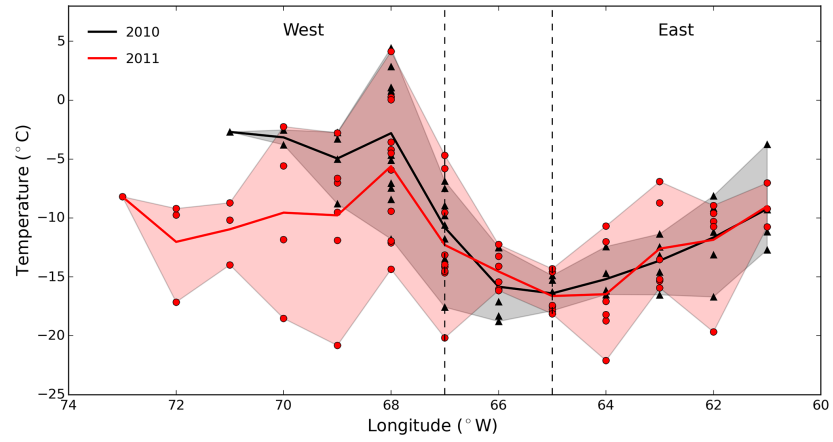

Figure 4. Atmospheric temperature as measured by the aircraft $\left({ }^{\circ} \mathrm{C}\right)$ as a function of longitude, averaged in $1^{\circ}$ longitude bins. The flightaveraged values are overplotted as black triangles (2010) and red circles (2011). Solid lines represent the average of these averages in each longitude bin. Shaded grey (2010) and red (2011) areas indicate the spread of these averages across the peninsula. The vertical dashed lines delimits the western and eastern regions of the peninsula as defined in this study.

formed daily at Rothera Research Station (not shown). The cold in the west is a result of air being pulled around the tip of the peninsula from the Weddell Sea, and this is confirmed by the back-trajectory analysis reported later in this paper. The relative humidity $(\mathrm{RH})$ plotted as a function of longitude (Fig. 5) shows more variability than the temperature record, and there is no clear difference between the years except an increase of RH in the west in 2010 in spite of the larger temperatures (Fig. 4), indicating an increased amount of water vapour at that time. 


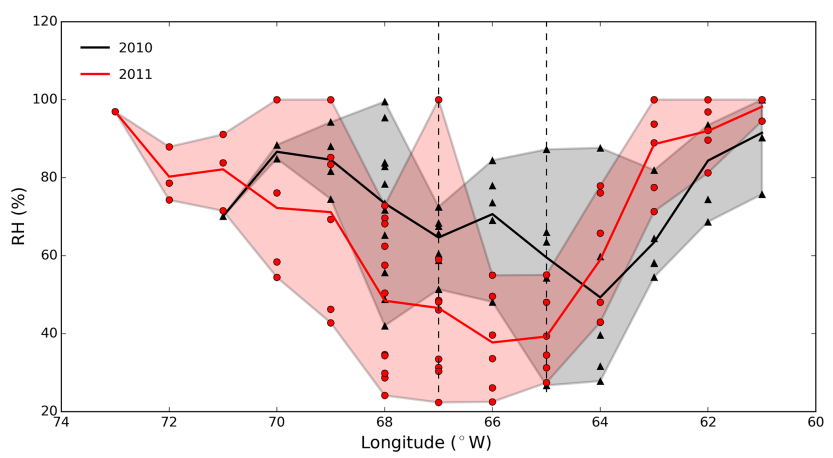

Figure 5. Same as Fig. 4 but for the relative humidity.

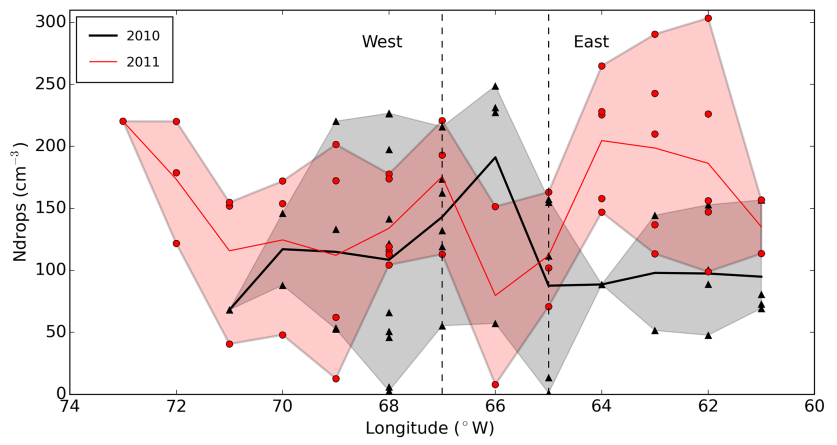

Figure 6. Same as Fig. 4 but for the liquid droplet number concentration $\left(\mathrm{cm}^{-3}\right)$.

\section{Results on clouds and aerosol measurements}

\subsection{Liquid phase in clouds}

The number concentration of liquid drops $\left(\mathrm{cm}^{-3}\right)$ averaged first over $1^{\circ}$ longitude bands for each flight as well as each band averaged for the 2 years is shown in Fig. 6. This means that each flight has the same weight, giving a more representative final value. This averaging method also means that a long flight in a particular longitude bin does not dominate the overall average. Each year is plotted separately with 2010 in black and 2011 in red. At each longitude bin the average from each individual flight is shown as a point - the small number of points at each longitude means that it is not reasonable to calculate the standard deviation, but the spread of the points gives some idea of the data variability. To improve statistics the data were binned further into two large bins, one on each side of the peninsula: one from 67 to $74^{\circ} \mathrm{W}$ and one from 60 to $65^{\circ} \mathrm{W}$. These values, along with their standard deviations, are reported in Table 1 . The CAS size spectrum showed peaked distributions around $8-12 \mu \mathrm{m}$, illustrating the condensational growth of supercooled droplets (not shown). The average number of droplets varies from around 60 to over $200 \mathrm{~cm}^{-3}$ (Fig. 6), which is typical of concentrations found over the open ocean away from possible sources of $\mathrm{CCN}$ from continental land masses (Pruppacher and Klett,

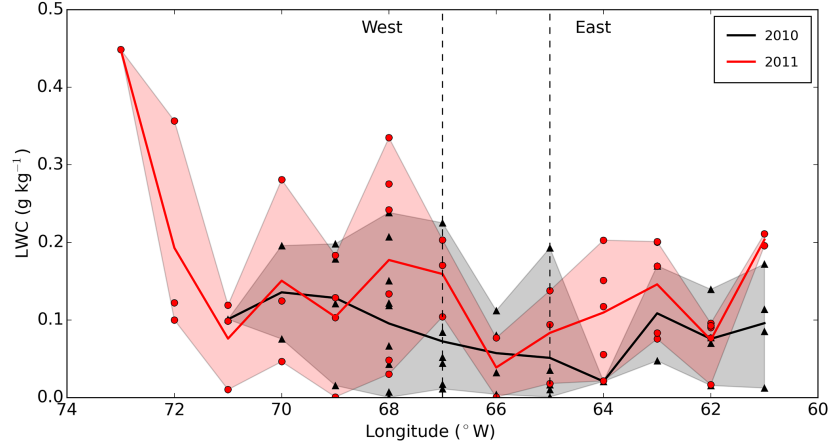

Figure 7. Same as Fig. 4 but for the liquid water content (LWC, $\mathrm{g} \mathrm{kg}^{-1}$ ).

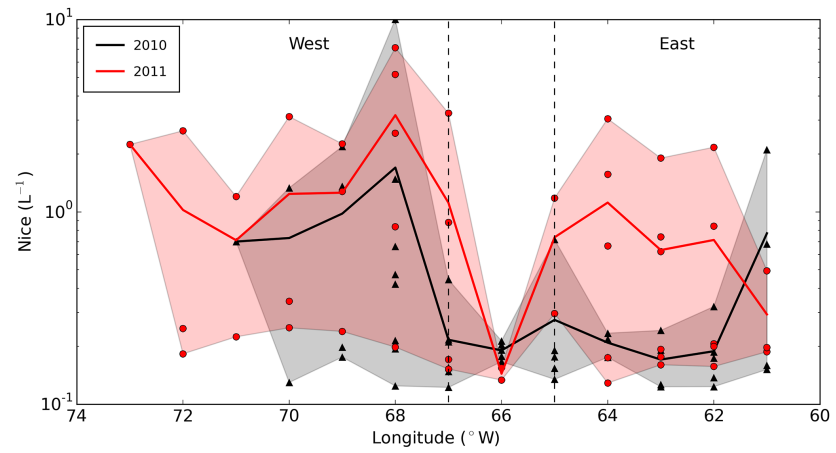

Figure 8. Same as Fig. 4 but for the number concentration of ice crystals $\left(\mathrm{L}^{-1}\right)$.

1997; Chubb et al., 2016). Table 2 gives the statistical significance of differences between both sides of the peninsula as well as differences between both years, using a $t$ test. The most significant difference (at the $99 \%$ level) for liquid drops is in the east of the peninsula between 2010 and 2011. A less significant but still noticeable difference exists between either side of the peninsula in 2011 (90\%). These relationships were not found in $2010(<80 \%)$.

The LWC in clouds averaged by longitude for the 2 years is shown in Fig. 7. Again to get better statistics, the values of LWC have been averaged on both sides of the peninsula using the same size longitude bins that were used for liquid drop numbers. A significant difference between the 2 years is found at the $90 \%$ level in the east and $95 \%$ level in the west (see Table 2), although the east-west difference in both years is not significant. The single point of high LWC in 2011 at $73^{\circ} \mathrm{W}$ is the result of a small number of flights into active frontal systems with large amounts of liquid water.

\subsection{Ice phase in clouds}

The ice particle numbers and ice water content, averaged in the same way as the drops in Fig. 6, are shown in Figs. 8 and 9 for areas in the cloud that were at least partially glaciated that is, non-circular particles were observed in the CIP. The 
Table 1. Average values for cloud measurements and out-of-cloud aerosols for both years and both sides of the peninsula. $\sigma(x)$ refers to the standard deviation of the variable $x$, and $N$ the number of flight averages available for the global eastern or western averages. LWC refers to liquid water content, and IWC to ice water content.

\begin{tabular}{|c|c|c|c|c|}
\hline & West 2010 & West 2011 & East 2010 & East 2011 \\
\hline Drops $\left(\mathrm{cm}^{-3}\right)$ & 124.27 & 154.62 & 103.26 & 191.68 \\
\hline$\sigma$ (Drops) & 68.6 & 63.52 & 68.98 & 71.62 \\
\hline$N$ & 23 & 23 & 20 & 22 \\
\hline LWC $\left(\mathrm{g} \mathrm{kg}^{-1}\right)$ & 0.094 & 0.157 & 0.069 & 0.108 \\
\hline$\sigma(\mathrm{LWC})$ & 0.07 & 0.12 & 0.06 & 0.07 \\
\hline$N$ & 23 & 23 & 20 & 22 \\
\hline Ice crystals $\left(\mathrm{L}^{-1}\right)$ & 1.025 & 1.730 & 0.362 & 0.737 \\
\hline$\sigma($ Ice crystals $)$ & 2.209 & 1.983 & 0.543 & 0.771 \\
\hline$N$ & 20 & 21 & 19 & 21 \\
\hline IWC $\left(\mathrm{g} \mathrm{kg}^{-1}\right)$ & 0.0107 & 0.0168 & 0.00344 & 0.0124 \\
\hline$\sigma(\mathrm{IWC})$ & 0.0155 & 0.0150 & 0.00349 & 0.0253 \\
\hline$N$ & 20 & 21 & 18 & 21 \\
\hline Aerosols $\left(\mathrm{cm}^{-3}\right)$ & 0.0692 & 0.105 & 0.106 & 0.218 \\
\hline$\sigma($ aerosols $)$ & 0.0678 & 0.129 & 0.153 & 0.314 \\
\hline$N$ & 53 & 77 & 59 & 87 \\
\hline
\end{tabular}

Table 2. Statistical significance of the differences between either year on either side of the peninsula as obtained from the $t$ test performed for the four cloud variables and the aerosols (see text for details). Values greater than $90 \%$ are highlighted in bold.

\begin{tabular}{lrrrrr}
\hline & $N$ (drops) & LWC & $N($ ice $)$ & IWC & $N$ (aerosols) \\
\hline W2010-W2011 & $83 \%$ & $\mathbf{9 6} \%$ & $71 \%$ & $79 \%$ & $\mathbf{9 3 \%}$ \\
E2010-E2011 & $\mathbf{9 9 \%}$ & $\mathbf{9 4} \%$ & $\mathbf{9 1 \%}$ & $85 \%$ & $\mathbf{9 8 \%}$ \\
E2010-W2010 & $68 \%$ & $78 \%$ & $77 \%$ & $\mathbf{9 4 \%}$ & $88 \%$ \\
E2011-W2011 & $93 \%$ & $89 \%$ & $\mathbf{9 6 \%}$ & $50 \%$ & $\mathbf{9 9 \%}$ \\
\hline
\end{tabular}

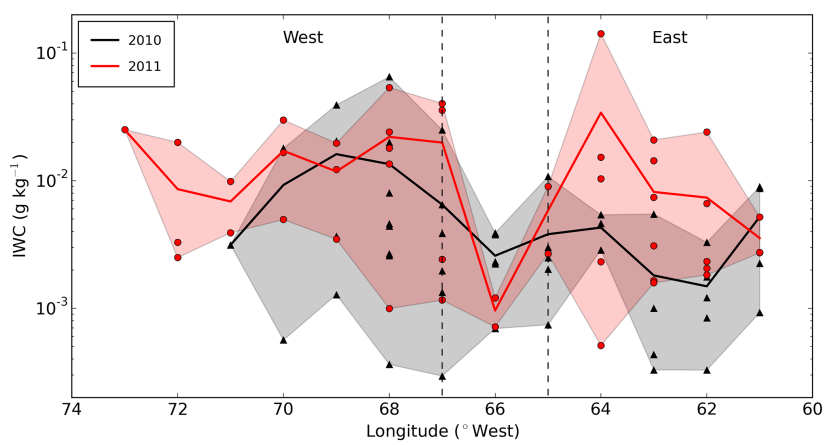

Figure 9. Same as Fig. 4, for the ice water content (IWC, $\mathrm{g} \mathrm{kg}^{-1}$ ).

number of ice particles observed is roughly 5 to 6 orders of magnitude lower than the number of cloud droplets, and the relative amplitude of the variability higher (the standard deviation of liquid droplet number concentration is about $50 \%$ of the average values, while it is as high as or higher than averages for ice crystal number concentrations). Also, not all the clouds investigated were glaciated to any extent, and so there are slightly fewer measurements (Table 1) for ice crystals than for the drops - except for the east of the peninsula in 2010 when there was an observation of a completely glaciated cloud. First looking at the number concentration of crystals, Fig. 8 and Table 1 show that in 2011 there were more crystals on both sides of the peninsula than in 2010. However, Table 1 shows the standard deviation of the crystal numbers is large. Table 2 shows that differences are not significant between the 2 years $(<80 \%)$ in the west, but significant in the east $(90 \%)$. Differences are also significant between either side of the peninsula in 2011 (at the $95 \%$ level), however not in 2010 (77\%).

The ice water content (Fig. 9) shows a similar trend to crystal numbers in Fig. 8. However, in this case using the averaged values on each side of the peninsula (Table 1), the difference between both sides in 2010 is significant at the $90 \%$ level.

The distribution of crystals with atmospheric temperature for the 2 years is shown in Fig. 10. Median ice crystal number concentrations have been derived over $0.5^{\circ} \mathrm{C}$ bins along with the associated median absolute deviations. The distributions 

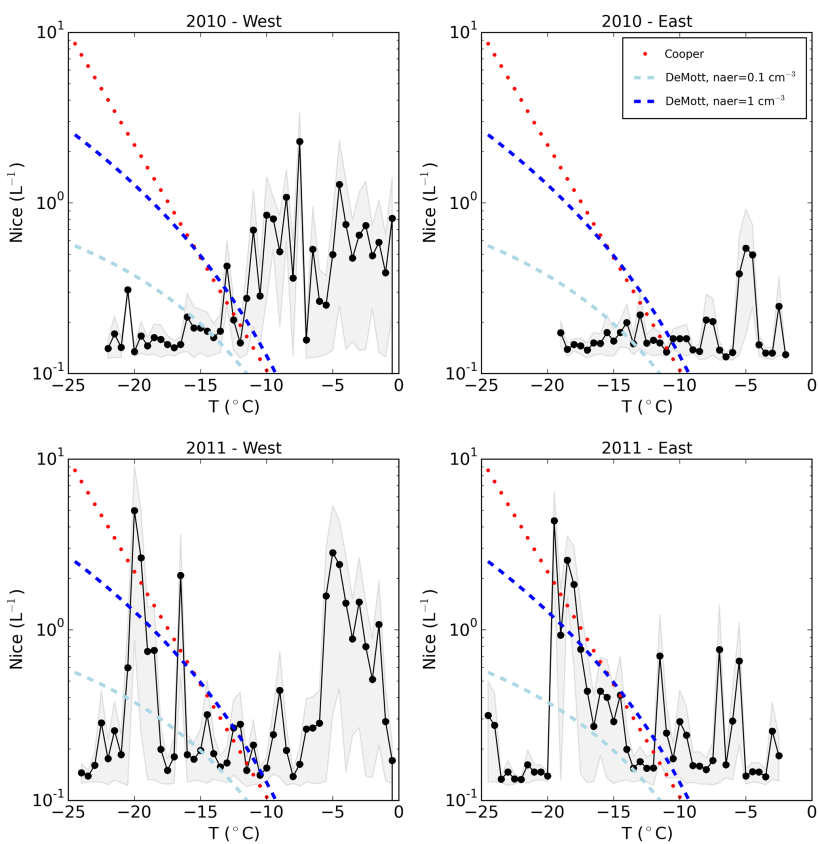

Figure 10. Distribution of ice crystals $\left(\mathrm{L}^{-1}\right)$ as a function of atmospheric temperatures for 2010 (top row) and 2011 (bottom row), for the western side (left column) and for eastern side (right column). The median of the number concentrations was derived per $0.5^{\circ} \mathrm{C}$ bins. The dotted and dashed lines show the predicted number of primary ice particles from two parameterization schemes (see text for details). The shaded area represents the median absolute deviation from the median value. West refers to $74-67^{\circ} \mathrm{W}$, and east refers to $65-60^{\circ} \mathrm{W}$.

are very different in the 2 years and between the east and west of the peninsula. In the west, both years have a peak ice number concentrations around $-5^{\circ} \mathrm{C}$. As reported by Grosvenor et al. (2012), for some of the 2010 flights only, this peak is most probably related to a secondary ice production process known as the Hallett-Mossop process (Hallett and Mossop, 1974). This consists of droplets shattering upon freezing when impinged by existing crystals (riming process), thus causing a cascade of crystals. This process only operates efficiently in a narrow temperature range (approximately -3 to $-8^{\circ} \mathrm{C}$ ) with an optimum around $-5^{\circ} \mathrm{C}$ and requires a large enough ratio of number concentrations of small drops (nS; < about $13 \mu \mathrm{m}$ ) to large drops (nL; > about $24 \mu \mathrm{m}$ ) (Mossop, 1985). Typical observed concentrations by Mossop (1985) of large (small) drops were $10-80 \mathrm{~cm}^{-3}\left(5-60 \mathrm{~cm}^{-3}\right)$, with the ratio $\mathrm{nS} / \mathrm{nL}$ ranging between 0.1 and 5 . In the present work, median values per flight for $\mathrm{nS}, \mathrm{nL}$, and $\mathrm{nS} / \mathrm{nL}$ (where peaked concentrations are observed at $-5^{\circ} \mathrm{C}$ ) are in the following respective ranges: $16-90 \mathrm{~cm}^{-3}, 9-33 \mathrm{~cm}^{-3}$, and $0.5-$ 13 (with flight minima always above 0.1 ). Note that no constrain is available in the present dataset to properly estimate the velocity of the riming particles. However, Mossop (1985) suggests that splintering can occur at velocities as low as $0.2 \mathrm{~m} \mathrm{~s}^{-1}$ and observes no abrupt drop of splinter produc- tion from 1 to $0.55 \mathrm{~m} \mathrm{~s}^{-1}$, meaning that the rimer velocity does not show a lower cut-off preventing the HallettMossop process from happening. In addition, other mechanisms known to trigger ice multiplication do not operate in the -8 to $-3^{\circ} \mathrm{C}$ temperature range but at colder temperatures $\left(<-10^{\circ} \mathrm{C}\right)$, for example ice-ice collision (Takahashi et al., 1995 and Yano and Phillips, 2011); freezing of large drops with ice spicules formation (Lawson et al., 2015); or breakup of crystals, which preferably requires irregular shapes like dendrites that are favoured at low temperatures (Bacon et al., 1998). The main limitation to an absolute identification of the process as Hallett-Mossop is the resolution (both temporal and spatial) of the CAPS probe to observe the process in detail from its start as only the resulting larger crystals are observed and not the first ice.

In the east there is no clear peak at the high temperatures $\left(>-10^{\circ} \mathrm{C}\right)$ in 2011 ; there is only a small peak in 2010 . It suggests that relatively less secondary ice production is observed for the eastern side of the peninsula. It can be seen that during 2011 the number of ice crystals increases from $-10^{\circ} \mathrm{C}$ to around $-20^{\circ} \mathrm{C}$, and this probably corresponds to primary ice production (where an INP active at a given temperature interacts with a droplet or vapour to form one crystal). Ice nuclei parameterizations relying either only on the temperature (Cooper, 1986) or on both the temperature and the aerosol $(>0.5 \mu \mathrm{m})$ concentration (DeMott et al., 2010) are plotted in Fig. 10. They are meant to account for primary ice nucleation and predict increasing INP concentrations from -10 to $-20^{\circ} \mathrm{C}$. For the DeMott et al. (2010) parameterization, aerosol concentrations bracketing the present average observations (Sect. 3.3, Fig. 11) were used as input. Comparing the trends of either of the parameterizations to the ice crystal distributions also strengthens the idea that the ice crystal distributions peaking around $-5^{\circ} \mathrm{C}$ are related to secondary ice production processes.

\subsection{Aerosols out of clouds}

It is to be expected that the number of drops and ice crystals will be controlled by the number of aerosols acting as $\mathrm{CCN}$ and INPs, excluding for the moment the role of secondary ice production. The instruments that were fitted to the Twin Otter in 2010 and 2011 did not allow the full range of aerosols to be measured. However the CAS, which is part of the CAPS probe, measures aerosol size distribution down to $0.5 \mu \mathrm{m}$. The zonal variation of aerosol particles greater than $0.5 \mu \mathrm{m}$ and less than $1 \mu \mathrm{m}$ is shown in Fig. 11, and their average numbers in both years and on both sides of the peninsula are given in Table 1. Note that to improve statistics and have a better picture of the aerosol population in the region, 55 flights were used, i.e. including flights not primarily intended to perform cloud measurements but still equipped with the CAPS probe. Table 2 gives the significance of aerosol differences between years and regions. If the single point in the far west in 2011 is excluded (which is from one flight 


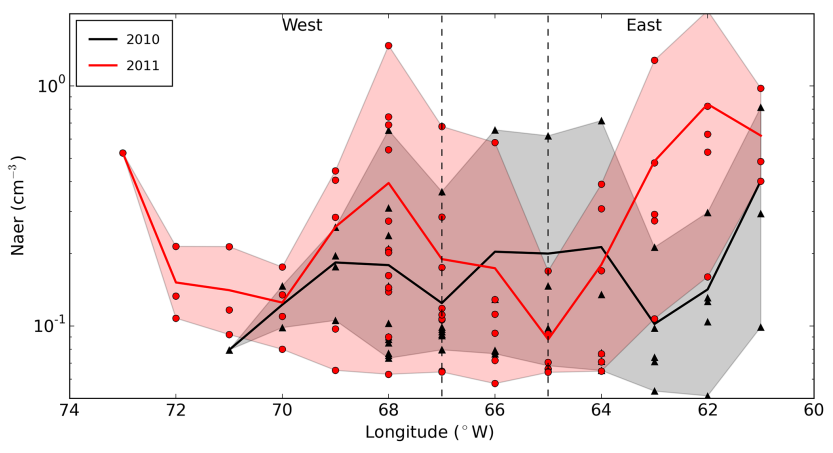

Figure 11. Same as Fig. 4 but for the number concentration of aerosols larger than $0.5 \mu \mathrm{m}$ and smaller than $1 \mu \mathrm{m}$ in diameter $\left(\mathrm{cm}^{-3}\right)$. Fifty-five flights are considered here (31 flights from both campaigns equipped with the CAPS probe but not intended for cloud measurements in addition to the 24 cloud flights) to increase the statistics and give better overview of the aerosol population across the peninsula for both years. See text (Sect. 3.3) for more details. The vertical dashed lines delimit the western and eastern regions of the peninsula as defined in this study.

and is considered an anomaly), the 2 years to the west of the peninsula are very similar. To the east there is a significant difference between the 2 years (at the $95 \%$ level), with 2011 having almost twice the concentration of aerosol as 2010. In 2011 there is also a significant difference between the east and west sides of the peninsula (at the $99 \%$ level), with twice the concentration of aerosol in the east as in the west of the peninsula. Importantly, the same conclusions are drawn when using the 24 cloud flights only.

\section{Discussion}

The variability of cloud droplets and ice concentration observed in this study is quite large, and the number of flights is small, compared to the number of measurements that have been made at mid-latitudes. This makes identifying statistically significant changes between geographical areas or between years difficult. This problem has been dealt with by first averaging the data into longitudinal bands (Figs. 6-9 and 11). Although this allows some of the differences of interest to be observed, there are still too few points to determine if these differences are significant. To help with this, averages were taken of all the data on each side of the peninsula (Table 1), and in this case clear statistical differences can be seen (Table 2).

\subsection{Aerosol source regions and liquid droplets}

The average number of cloud droplets in the clouds (see Fig. 6) varies over a large range from just a few to almost $300 \mathrm{~cm}^{-3}$, and this probably reflects the large range in $\mathrm{CCN}$ found in the coastal areas of Antarctica. The mean droplet number concentration on each side of the peninsula is not untypical of values found in the mid-ocean (Pruppacher and
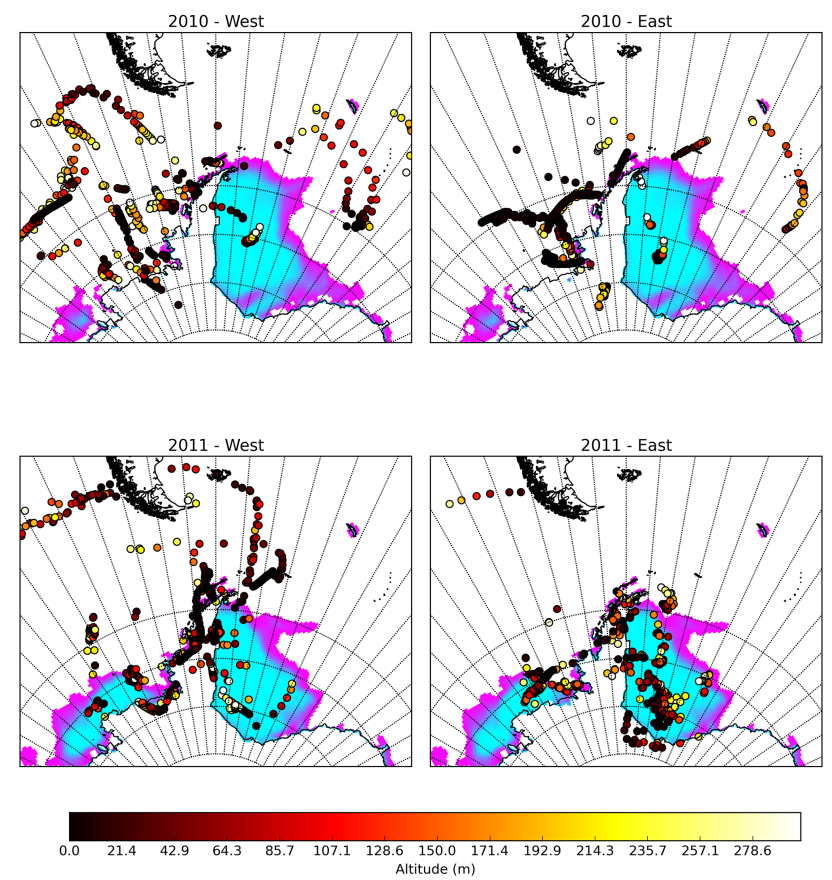

Figure 12. Location and altitudes (colour-coded, in $\mathrm{m}$ ) of lowaltitude ( $\leq 300 \mathrm{~m}$ above ground) air masses $48 \mathrm{~h}$ prior to reaching a flight track (from either of the 55 flights used in Fig. 11) west (left column) or east (right column) of the peninsula. Over-plotted is the monthly averaged sea ice fractional coverage as obtained from Nimbus-7 SMMR daily data at $25 \mathrm{~km}$ resolution (see text for reference) (lightest blue is $>90 \%$, darkest blue is $50 \%$, dark magenta is $25 \%$, and lightest magenta is below $1 \%$ ). West refers to $74-67^{\circ} \mathrm{W}$, and east refers to $65-60^{\circ} \mathrm{W}$.

Klett, 1997; Chubb et al., 2016) and reflects the position of Rothera exposed to air masses with origins in the South Pacific. Table 2 shows that it is only in the east that there is a significant difference (at the $99 \%$ level) between the 2 years in the aerosol concentration, and this might be a result of the different source regions for particles between the 2 years.

To test this hypothesis, back-trajectory analysis using the Hybrid Single-Particle Lagrangian Integrated Trajectory (HYSPLIT) model has been performed (Stein et al., 2015). Seven-day back trajectories were calculated using the National Centers for Environmental Prediction (NCEP) reanalysis meteorological field with starting points located at $60 \mathrm{~s}$ intervals along the track of each flight. Figure 12 shows the position of the low-altitude ( $\leq 300 \mathrm{~m}$ a.s.l.; see below) air masses $48 \mathrm{~h}$ backwards, along with their altitude (colour-coded), for both years and sides of the peninsula. The sea ice fractional coverage (at $25 \mathrm{~km}$ resolution), obtained from Nimbus-7 Multichannel Microwave Radiometer (SMMR) and Defense Meteorological Satellite Program (DMSP) SSM/I-SSMIS passive microwave data (Cavalieri et al., 1996), has been over plotted in blue. As in Sect. 3.3 (and in Fig. 11) 55 flights were used to investigate the average origin of the air masses in both years. A striking difference 
Table 3. Relative proportion of low-altitude $(<300 \mathrm{~m})$ air masses passing over sea-ice-covered regions with respect to the total number of low-altitude air masses along all back trajectories derived from the HYSPLIT model for 55 flight tracks from both campaigns (see text for details). In parentheses, the same percentages but for the 24 flights only. Relative proportions are indicated for both years and both sides of the peninsula, with the side referring to the (start) ending point of the air mass (back) trajectory. Percentages are computed over different time ranges, prior to reaching a given point of a flight track on either side. A region is considered as covered by sea ice as long as the sea ice concentration from the NIMBUS-7 SMMR is larger than $1 \%$ (see Sect. 4.1 for reference).

\begin{tabular}{lrrrr}
\hline & East 2011 & East 2010 & West 2011 & West 2010 \\
\hline Last 72h & $61 \%(43)$ & $35 \%(47)$ & $37 \%(21)$ & $24 \%(9)$ \\
Last 48h & $58 \%(80)$ & $45 \%(60)$ & $37 \%(22)$ & $25 \%(8)$ \\
Last 24h & $48 \%(94)$ & $68 \%(91)$ & $34 \%(26)$ & $26 \%(8)$ \\
Last 12h & $97 \%(100)$ & $90 \%(98)$ & $33 \%(19)$ & $15 \%(7)$ \\
\hline
\end{tabular}
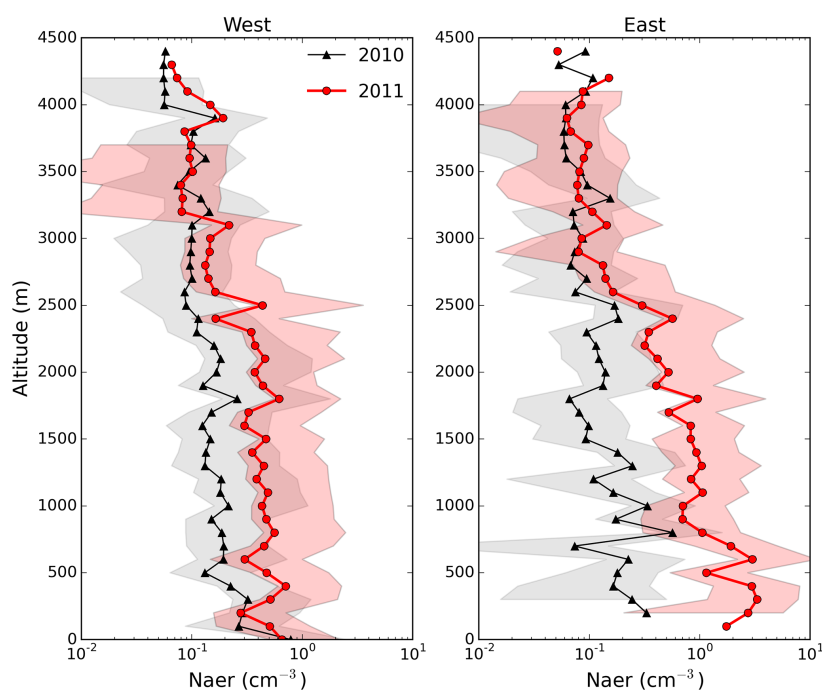

Figure 13. Averaged vertical profiles of number concentration of aerosols $\left(\mathrm{cm}^{-3}\right)$ on both sides of the peninsula over all the flights (as for Fig. 11). Shaded areas indicate the spread of the data between absolute minimum and maximum values at each level. West refers to $74-67^{\circ} \mathrm{W}$, and east refers to $65-60^{\circ} \mathrm{W}$.

appears between 2010 and 2011, with 2011 showing more sources above the sea ice. Table 3 summarizes the relative proportion of air masses passing above sea ice compared to above open water/ice shelf (referred to as "other") among all low-altitude air masses (i.e. below $300 \mathrm{~m}$, approximate boundary layer height; Fiedler et al., 2010) and along all the back trajectories. The relative proportions are also indicated for the case when only the 24 cloud flights are used (number in parentheses in Table 3). We first comment on the analysis using the 55 flights. A sea-ice-covered region was defined as a region where fractional coverage is larger than $1 \%$ (however the sea ice regions of interest in Table 3 normally have much larger values; see Fig. 12). These low-altitude air masses will have greater sensitivity to surface aerosol emissions. The statistics integrated over different durations are shown to illustrate the consistently dominating or increasing trends of the relative contributions of sea-ice low-altitude air masses among all low-altitude air masses. Whatever the time interval, low-altitude air masses sampled to the east of the peninsula always overpass sea ice regions relatively more often than they overpass other regions - with the influence of the sea ice being greater in 2011. Looking at Table 3, we can see that the sea ice has most influence, over most time periods, in the east in 2011, then less in the east in 2010, less again in the west in 2011, and least in the west in 2010. Thus, Table 3, along with Fig. 12, shows that (a) air sampled in the east is more sea-ice-influenced than air sampled in the west in both years, (b) air sampled in the east in 2011 has had a relatively longer sea ice track at low altitudes than in 2010, and (c) air sampled in the west in 2011 is more sea-ice-influenced than in 2010. Looking at the analysis restrained over the 24 cloud flights only, the above (b) statement becomes less clear as only the analysis over the period covering the previous $48 \mathrm{~h}$ shows a clear increase of sea ice influence in the east in 2011 (Table 3, second line), compared to 2010, but statement (a) and (c) still prevail and are even strengthened when considering these smaller statistics. Overall clear differences appear in the origin of the air masses when splitting the analysis into west-east and 2010-2011 comparisons. The larger concentration of aerosols in 2011, especially on the eastern side (Fig. 11), compared to 2010 (Table 2) could be explained by more air masses having longer tracks at low level over seaice-covered regions of the Weddell Sea. It is possible that sea salt on the snow-covered surface of the sea ice could easily be lofted into the air as blowing snow which sublimes to form sea salt aerosol. This has been suggested as an efficient mechanism for getting sea salt aerosol, which could act as CCN, into the boundary layer (Yang et al., 2008). This suggests that the increase in droplet number concentrations seen in 2011 on the eastern side of the peninsula (Fig. 6) could result from the increase in aerosol numbers. Figure 13 shows average vertical profiles of aerosol number concentration on both sides of the peninsula for 2010 (blue circle) and 2011 (red triangles), for the 55 flights used in Sect. 3.3 (note that the same vertical profiles plotted with the 24 cloud flights show similar differences between the years). The corresponding shaded areas indicate absolute minimum and maximum (non-null) values at each altitude level over the respective campaigns. Like the latitudinal averages of aerosols shown in Fig. 11, Fig. 13 shows that the interannual differences in aerosol concentration on the eastern side are much more pronounced (see the $99 \%$ significance level in Table 2) than on the western side (93\% significance level). Interestingly, these differences occur almost exclusively below $2000-2500 \mathrm{~m}$. Above that altitude, the concentration of aerosols is similar between both years and both sides (around $0.1-0.2 \mathrm{~cm}^{-3}$ ). The central part of the peninsula between $67^{\circ} \mathrm{W}$ and $65^{\circ} \mathrm{W}$ is also character- 

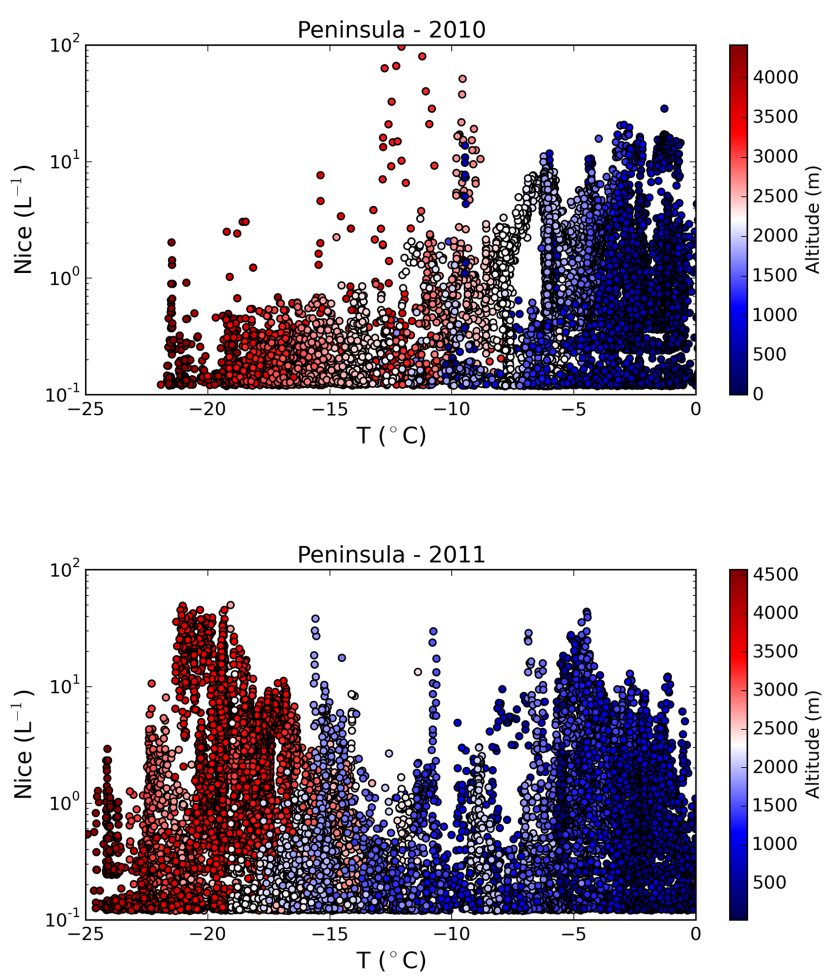

Figure 14. Distribution of all measurements of ice crystals $\left(\mathrm{g}^{-1}\right)$ as a function of atmospheric temperatures for 2010 (top) and 2011 (bottom) for the whole peninsula. Colour indicates the altitude of the measurement, with light to dark red referring to increasing altitudes above $\approx 2500 \mathrm{~m}$ and colours from light to dark blue referring to altitudes decreasing below $\approx 2250 \mathrm{~m}$.

ized by this concentration of about $0.1 \mathrm{~cm}^{-3}$ (not shown). This suggests that a homogeneous mixture of aerosols (at least in terms of number concentration, if not nature) prevails at altitudes above the height of the peninsula mountain barrier. Conversely, at lower levels, the Antarctic Peninsula barrier would help sustain different pools of aerosols on either of its sides. These aerosol pools could give rise to different cloud microphysics on either side of the peninsula, and a possible interpretation of the observations is that the increased number of droplets in the east in 2011 compared to 2010 could be the result of an environment more influenced by particle originating from sea ice regions.

\subsection{Ice production, altitude ranges, and aerosols}

Interestingly, the ice crystal number concentration (Fig. 8) does not follow the same pattern as the liquid droplets. A significant difference (at the $95 \%$ level) is seen between the 2 years in the west, and a similar significant difference is also seen between both sides of the peninsula in 2011. However, this is not unexpected as, while aerosols are the source of CCN and INPs so that a correlation between the numbers of liquid drops and ice crystals might be expected, there is another process going on to create ice crystals. This is the secondary ice production due to the Hallett-Mossop process for temperatures warmer than $-10^{\circ} \mathrm{C}$ (introduced in Sect. 3.2). The peak of ice crystal numbers at temperatures above $-10^{\circ} \mathrm{C}$ can be clearly seen (Fig. 10), especially in the west, where as might be expected the temperatures are warmer. This is illustrated by Fig. 4, which shows each year's temperatures averaged by latitude along the aircraft tracks. In the east there is much less evidence of secondary ice formation for both years (Fig. 10), and this correlates with the similarly lower temperatures in both years (Fig. 4). At temperatures below $-10^{\circ} \mathrm{C}$ (Fig. 10) it can be seen that in 2011 there is a distinct peak in ice concentration, which suggests more primary ice production (see Sect. 3.2) in both the west and the east at temperatures approximately ranging between -10 and $-20^{\circ} \mathrm{C}$, while there is almost virtually no primary ice production peak in 2010. Figure 14 shows the entire dataset of crystal distribution with temperatures for the 2 years (both sides at the same time) colour-coded with the altitude of the observation. The primary ice production mainly occurs at altitudes above roughly $2500 \mathrm{~m}$, while the secondary ice production occurs almost exclusively below $2000 \mathrm{~m}$ - this of course is related to atmospheric lapse rate. This means that the primary ice production peak presence cannot be solely related to the increase of aerosols, which is observed mostly below $2500 \mathrm{~m}$ (see Sect. 4.1). As such, the lower primary ice production in 2010, and its presence in 2011 on both sides of the peninsula, can be linked to the colder 2011 temperatures compared to the 2010 temperature above $2500 \mathrm{~m}$ (not shown). Another possible factor in the lower ice production in 2010 is the different nature of INPs due to different air mass histories. It can be seen that in 2011 more air masses were coming from above sea ice regions (see Sect. 4.1). It has been suggested that biogenic particles found in sea ice could act as INPs (Burrows et al., 2013), and the same method for transferring from sea ice to the atmosphere (as the sea salt) could explain the different nature of INPs found in 2011 above $2500 \mathrm{~m}$, leading to more primary ice production in 2011.

\section{Summary and conclusion}

Figure 15 summarizes the results reported in this paper. Our observations show the significant differences in cloud properties between the two measurement periods, February 2010 and January 2011, and between measurements made to the east and to the west of the Antarctic Peninsula, and they present some possible explanation for those.

January 2011 showed almost twice as many aerosols on the eastern side of the peninsula as on the western side, and more than in the previous year. The larger number of droplets in 2011 can be explained by an increase of CCN that can be inferred from the observed increase in large aerosols $(>0.5 \mu \mathrm{m})$ in that year. The larger number concentrations of aerosols can be linked to the different source regions. In 


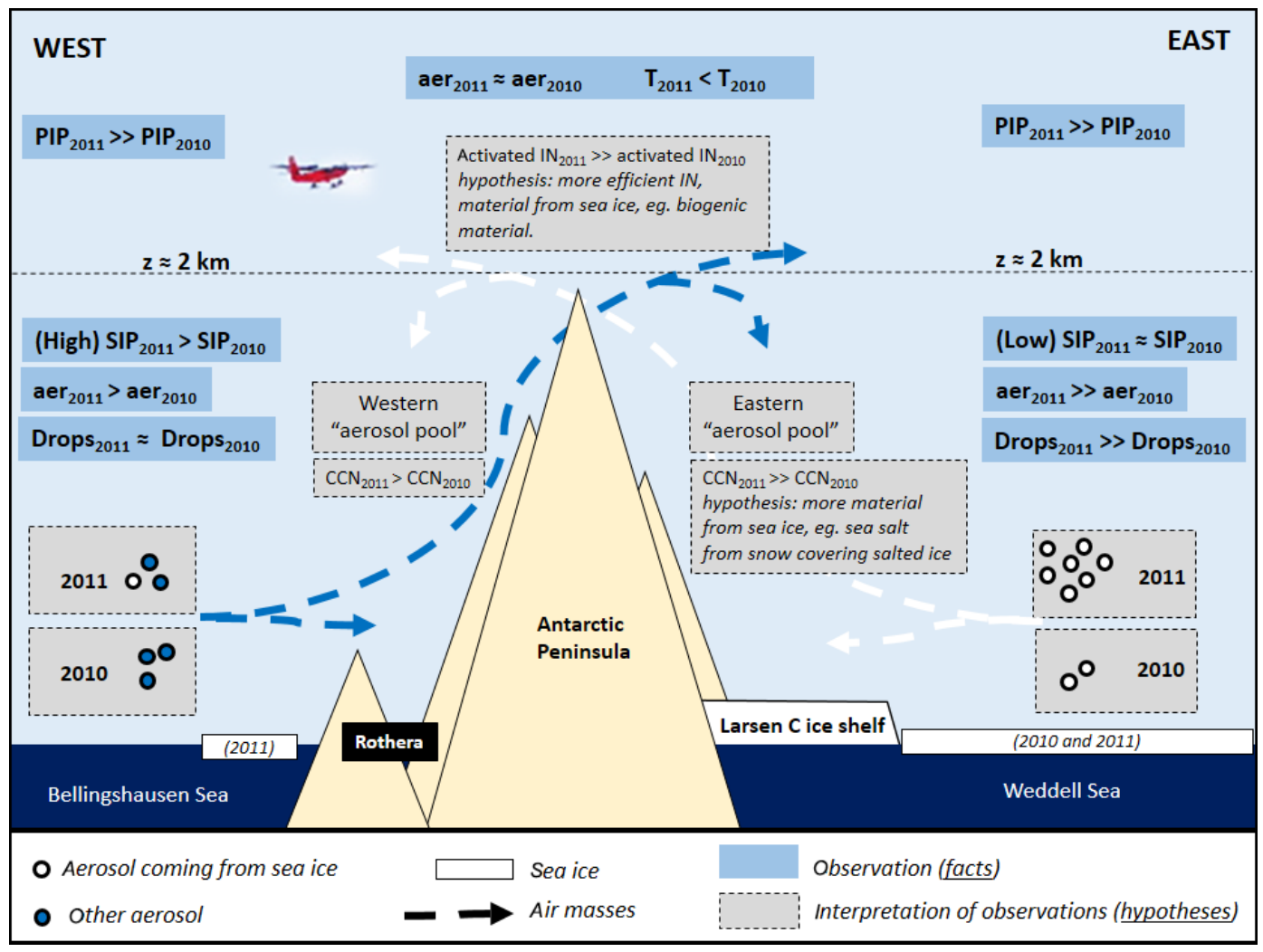

Figure 15. Schematic summarizing main observations from aircraft measurements from both periods of interests (February 2010 and January 2011) and on both sides of the Antarctic Peninsula (blue rectangles), as well as hypotheses (grey-framed rectangles) proposed to explain observations, as presented in the Discussion (Sect. 4). PIP refers to primary ice production, while SIP refers to secondary ice production, as presented in Sect. 3.2 .

2011, relatively more air masses were coming from the sea ice, and relatively more on the eastern side than on the western side. This brings a possibly interesting explanation to the twice-larger number of droplets in 2011 in the east (approximately $200 \mathrm{~cm}^{-3}$ ) compared to 2010 in the east, and also $50 \%$ larger than 2011 in the west.

The Hallett-Mossop secondary ice multiplication (at temperatures warmer than $-10^{\circ} \mathrm{C}$, peaking around $-5^{\circ} \mathrm{C}$ ) process seems to be key to the ice production mechanism below $2500 \mathrm{~m}$ on both sides of the peninsula, and mainly on the warmer western side. In contrast above $2500 \mathrm{~m}$ the primary ice production mechanism is expected to dominate. The larger production of primary ice crystals (at temperatures colder than $-10^{\circ} \mathrm{C}$, peaking around $-20^{\circ} \mathrm{C}$ ) above $2500 \mathrm{~m}$ in 2011 compared to 2010 on both sides of the peninsula is due to colder temperatures (activating more INPs) and the possibly different nature of INPs (coming relatively more from above sea ice regions). Indeed, there is only a small increase in number concentration of large $(>0.5 \mu \mathrm{m})$ aerosols in 2011 above $2500 \mathrm{~m}$. This is why the increase in aerosol number supports the larger amounts of liquid droplets but does not seemingly support the larger number of primary ice seen above $2500 \mathrm{~m}$ in 2011 on both sides of the peninsula. These observations show that the concentration of large aerosols $(>0.5 \mu \mathrm{m})$ is fairly similar across the peninsula (about $0.1-0.2 \mathrm{~cm}^{-3}$ ) at altitudes higher than the mountain barrier where dynamics would sustain a well-mixed aerosol population. Conversely, the mountains would favour the creation of so-called aerosol pools on either side of the peninsula, with different concentrations and nature that would be responsible for a different microphysics. Similarly, ice production is affected by the temperatures prevailing on either side of the peninsula, with little secondary ice production occurring on the eastern (colder) side and more on the (warmer) western side. The mountain's height controls the altitude at which both sides display similar primary ice production peaks above $2500 \mathrm{~m}$, because of similar population of aerosols.

The number of liquid drops and primary ice crystals is correlated with the sources of the air masses. These results indicate that the sea-ice-covered Weddell Sea could be a more important source of CCN and INPs than the open ocean. This may have more general implications for the microphysics of clouds that cover the Southern Ocean. The Southern Ocean is an area in which large errors have been identified in the simulated cloud cover, leading to large radiation biases in 
global climate models (Flato et al., 2013; Bodas-Salcedo et al., 2014). Given that, in winter, sea ice can extend up to $60^{\circ} \mathrm{S}$ and even $55^{\circ} \mathrm{S}$ in some regions, sources of $\mathrm{CCN}$ and INPs related to the sea ice could potentially have a large impact on the microphysics of clouds forming over the Southern Ocean, as they seem to have across the Antarctic Peninsula.

The present study is the very first of its kind attempting to depict cloud microphysics and aerosols across the Antarctic Peninsula from a small amount of flights; the scenario we suggest hopefully will stimulate other studies and measurements to better assess the plausibility of our interpretations.

\section{Data availability}

The data are being formatted for inclusion in the Polar Data Centre and will be available soon.

Acknowledgements. This work would not have been possible without the help of the scientists and support staff who helped in the Antarctic. We thank the editor and two anonymous reviewers for their comments, which helped improve the manuscript. The work was funded by UK Natural Environment Research Council with core funding and under grant NE/K01305X/1 and under NERC grant NEB1134.

Edited by: M. Krämer

Reviewed by: two anonymous referees

\section{References}

Bacon, N. J., Swanson, B. D., Baker, M. B., and Davis, E. J.: Breakup of levitated frost particles, J. Geophys. Res., 103, 13763-13775, 1998.

Baumgardner, D., Jonsson, H., Dawson, W., O'Connor, D., and Newton, R.: The cloud, aerosol and precipitation spectrometer: a new instrument for cloud investigations, Atmos. Res., 59-60, 251-264, doi:10.1016/S0169-8095(01)00119-3, 2001.

Belosi, F., Santachiara, G., and Prodi, F.: Ice-forming nuclei in Antarctica: New and past measurements, Atmos. Res., 145-146, 105-111, doi:10.1016/j.atmosres.2014.03.030, 2014.

Bodas-Salcedo, A., Williams, K. D., Ringer, M. A., Beau, I., Cole, J. N. S., Dufresne, J.-L., Koshiro, T., Stevens, B., Wang, Z., and Yokohata, T.: Origins of the Solar Radiation Biases over the Southern Ocean in CFMIP2 Models*, J. Climate, 27, 41-56, doi:10.1175/JCLI-D-13-00169.1, 2014.

Bromwich, D. H., Nicolas, J. P., Hines, K. M., Kay, J. E., Key, E. L., Lazzara, M. A., Lubin, D., McFarquhar, G. M., Gorodetskaya, I. V., Grosvenor, D. P., Lachlan-Cope, T., and Van Lipzig, N. P. M.: Tropospheric clouds in Antarctica, Rev. Geophys., 50, 1-40, doi:10.1029/2011RG000363, 2012.

Bromwich, D. H., Otieno, F. O., Hines, K. M., Manning, K. W., and Shilo, E.: Comprehensive evaluation of polar weather research and forecasting model performance in the Antarctic, J. Geophys. Res.-Atmos., 118, 274-292, doi:10.1029/2012JD018139, 2013.
Brown, P. R. A. and Francis, P. N.: Improved Measurements of the Ice Water Content in Cirrus Using a Total-Water Probe, J. Atmos. Ocean. Tech., 12, 410-414, doi:10.1175/15200426(1995)012<0410:IMOTIW>2.0.CO;2, 1995.

Burrows, S. M., Hoose, C., Pöschl, U., and Lawrence, M. G.: Ice nuclei in marine air: biogenic particles or dust?, Atmos. Chem. Phys., 13, 245-267, doi:10.5194/acp-13-245-2013, 2013.

Cavalieri, D. J., Parkinson, C. L., Gloersen, P., and Zwally, H. J.: Sea Ice Concentrations from Nimbus-7 SMMR and DMSP SSM/I-SSMIS Passive Microwave Data, Version 1, Sea Ice Concentrations from Nimbus-7 SMMR, Boulder, CO, USA, NASA National Snow and Ice Data Center Distributed Active Archive Center, available at: doi:10.5067/8GQ8LZQVL0VL (last access: January 2016), 1996.

Chubb, T., Huang, Y., Jensen, J., Campos, T., Siems, S., and Manton, M.: Observations of high droplet number concentrations in Southern Ocean boundary layer clouds, Atmos. Chem. Phys., 16, 971-987, doi:10.5194/acp-16-971-2016, 2016.

Cooper, W. A.: Ice Initiation in Natural Clouds, Meteor. Mon., 21, 29-32, doi:10.1175/0065-9401-21.43.29, 1986.

Crosier, J., Bower, K. N., Choularton, T. W., Westbrook, C. D., Connolly, P. J., Cui, Z. Q., Crawford, I. P., Capes, G. L., Coe, H., Dorsey, J. R., Williams, P. I., Illingworth, A. J., Gallagher, M. W., and Blyth, A. M.: Observations of ice multiplication in a weakly convective cell embedded in supercooled mid-level stratus, Atmos. Chem. Phys., 11, 257-273, doi:10.5194/acp-11-257-2011, 2011.

DeMott, P. J., Prenni, A. J., Liu, X., Kreidenweis, S. M., Petters, M. D., Twohy, C. H., Richardson, M. S., Eidhammer, T., and Rogers, D. C.: Predicting global atmospheric ice nuclei distributions and their impacts on climate, P. Natl. Acad. Sci. USA, 107, 1121711222, doi:10.1073/pnas.0910818107, 2010.

Elvidge, A. D., Renfrew, I. A., King, J. C., Orr, A., and LachlanCope, T. A.: Foehn warming distributions in nonlinear and linear flow regimes: a focus on the Antarctic Peninsula, Q. J. Roy. Meteor. Soc., 142, 618-631, doi:10.1002/qj.2489, 2014.

Fiedler, E. K., Lachlan-Cope, T. A., Renfrew, I. A., and King, J. C.: Convective heat transfer over thin ice covered coastal polynyas, J. Geophys. Res., 115, C10051, doi:10.1029/2009JC005797, 2010.

Flato, G., Marotzke, J., Abiodun, B., Braconnot, P., Chou, S. C., Collins, W., Cox, P., Driouech, F., Emori, S., Eyring, V., Forest, C., Gleckler, P., Guilyardi, E., Jakob, C., Kattsov, V., Reason, C., and Rummukainen, M.: Evaluation of Climate Models, Clim. Chang. 2013 Phys. Sci. Basis. Contrib. Work. Gr. I to Fifth Assess. Rep. Intergov. Panel Clim. Chang., 741-866, doi:10.1017/CBO9781107415324, 2013.

Fretwell, P., Pritchard, H. D., Vaughan, D. G., Bamber, J. L., Barrand, N. E., Bell, R., Bianchi, C., Bingham, R. G., Blankenship, D. D., Casassa, G., Catania, G., Callens, D., Conway, H., Cook, A. J., Corr, H. F. J., Damaske, D., Damm, V., Ferraccioli, F., Forsberg, R., Fujita, S., Gim, Y., Gogineni, P., Griggs, J. A., Hindmarsh, R. C. A., Holmlund, P., Holt, J. W., Jacobel, R. W., Jenkins, A., Jokat, W., Jordan, T., King, E. C., Kohler, J., Krabill, W., Riger-Kusk, M., Langley, K. A., Leitchenkov, G., Leuschen, C., Luyendyk, B. P., Matsuoka, K., Mouginot, J., Nitsche, F. O., Nogi, Y., Nost, O. A., Popov, S. V., Rignot, E., Rippin, D. M., Rivera, A., Roberts, J., Ross, N., Siegert, M. J., Smith, A. M., Steinhage, D., Studinger, M., Sun, B., Tinto, B. K., Welch, B. C., Wilson, D., Young, D. A., Xiangbin, C., and Zirizzotti, A.: 
Bedmap2: improved ice bed, surface and thickness datasets for Antarctica, The Cryosphere, 7, 375-393, doi:10.5194/tc-7-3752013, 2013.

Grosvenor, D. P., Choularton, T. W., Lachlan-Cope, T., Gallagher, M. W., Crosier, J., Bower, K. N., Ladkin, R. S., and Dorsey, J. R.: In-situ aircraft observations of ice concentrations within clouds over the Antarctic Peninsula and Larsen Ice Shelf, Atmos. Chem. Phys., 12, 11275-11294, doi:10.5194/acp-12-11275-2012, 2012.

Hallett, J. and Mossop, S. C. C.: Production of secondary ice particles during the riming process, Nature, 249, 26-28, doi:10.1038/249026a0, 1974

King, J. C., Lachlan-Cope, T. A., Ladkin, R. S., and Weiss, A.: Airborne Measurements in the Stable Boundary Layer over the Larsen Ice Shelf, Antarctica, Bound.-Lay. Meteorol., 127, 413428, doi:10.1007/s10546-008-9271-4, 2008.

King, J. C., Gadian, A., Kirchgaessner, A., Kuipers Munneke, P., Lachlan-Cope, T. A., Orr, A., Reijmer, C., van den Broeke, M., van Wessem, J., and Weeks, M.: Validation of the summertime surface energy budget of Larsen C Ice Shelf (Antarctica) as represented in three high-resolution atmospheric models, J. Geophys. Res., 1335-1347, doi:10.1002/2014JD022994, 2015.

Lachlan-Cope, T.: Antarctic clouds, Polar Res., 29, 150-158, doi:10.1111/j.1751-8369.2010.00148.x, 2010.

Lachlan-Cope, T. A., Ladkin, R., Turner, J., and Davison, P.: Observations of cloud and precipitation particles on the Avery Plateau, Antarctic Peninsula, Antarct. Sci. 13, 339-348, 2001.

Lawson, R. P., Woods, S., and Morrison, H.: The Microphysics of Ice and Precipitation Development in Tropical Cumulus Clouds, J. Atmos. Sci., 72, 2429-2445, doi:10.1175/JAS-D-14-0274.1, 2015.

Mossop, S. C.: Secondary ice particle production during rime growth: the effect of drop size distribution and rimer velocity, Q. J. Roy. Meteol. Soc., 111, 1113-1124, 1985.
Pruppacher, H. R. and Klett, J. D.: Microphysics of Clouds and Precipitation, Kluwer Academic Publishers, Dordrecht, the Netherlands, 1997.

Saxena, V. K.: Evidence of the Biogenic Nuclei Involvement in Antarctic Coastal Clouds, J. Phys. Chem., 87, 4130-4134, 1983.

Stein, A. F., Draxler, R. R., Rolph, G. D., Stunder, B. J. B., Cohen, M. D., and Ngan, F.: NOAA's HYSPLIT atmospheric transport and dispersion modeling system, B. Am. Meteorol. Soc., 2015, 2059-2077, doi:10.1175/BAMS-D-14-00110.1, 2015.

Takahashi, T., Nagao, Y., and Kushiyama, Y.: Possible High Ice Particle Production during Graupel-Graupel Collisions, J. Atmos. Sci., 52(24), 4523-4527, doi:10.1175/15200469(1995)052<4523:PHIPPD>2.0.CO;2, 1995.

Taylor, J. W., Choularton, T. W., Blyth, A. M., Liu, Z., Bower, K. N., Crosier, J., Gallagher, M. W., Williams, P. I., Dorsey, J. R., Flynn, M. J., Bennett, L. J., Huang, Y., French, J., Korolev, A., and Brown, P. R. A.: Observations of cloud microphysics and ice formation during COPE, Atmos. Chem. Phys., 16, 799-826, doi:10.5194/acp-16-799-2016, 2016.

Thompson, G. and Eidhammer, T.: A study of aerosol impacts on clouds and precipitation development in a large winter cyclone, J. Atmos. Sci., 71, 3636-3658, doi:10.1175/JAS-D-13-0305.1, 2014.

Yang, X., Pyle, J. A., and Cox, R. A.: Sea salt aerosol production and bromine release: Role of snow on sea ice, Geophys. Res. Lett., 35, L16815, doi:10.1029/2008GL034536, 2008.

Yano, J.-I. and Phillips, V. T. J.: Ice-Ice Collisions: An Ice Multiplication Process in Atmospheric Clouds, J. Atmos. Sci., 68, 322-333, doi:10.1175/2010JAS3607.1, 2011. 